\title{
Escala de Atribuições de Causalidade de Estudantes do Ensino Fundamental (EAVAT-EF)
}

\author{
Evely Boruchovitch ${ }^{*}$ \\ Universidade Estadual de Campinas, Campinas, SP, Brasil \\ Acácia Aparecida Angeli dos Santos \\ Universidade São Francisco, Itatiba, SP, Brasil
}

\begin{abstract}
RESUMO
O presente trabalho teve como objetivo de examinar as propriedades psicométricas de uma escala de atribuição de causalidade para sucesso e fracasso escolar para alunos do Ensino Fundamental. A escala foi construída com originalmente 55 itens fechados em forma de escala Likert, de três pontos, relacionados às dimensões locus e controlabilidade da causa. Foi aplicada a uma amostra de 668 estudantes do Ensino Fundamental. A análise fatorial revelou o bom funcionamento de 35 itens e uma estrutura bifatorial: fator 1 - causas para fracasso e 2 causas para o sucesso. Os índices de consistência interna, aferidos pelo Alpha de Cronbach, foram 0,91, respectivamente, para a escala total, 0,92 para o fator 1 e 0,83 para o 2 . A variância total explicada foi de $29,03 \%$. Espera-se que a escala possa ser útil a pesquisadores e educadores.

Palavras-chave: atribuição causal; educação básica; construção de escala.
\end{abstract}

\section{ABSTRACT \\ Causal Attribution Scale for Elementary School Students}

The aim of this paper was to examine the psychometric properties of a causal attribution scale for school success and failure for basic education students. The scale was constructed based on the Attribution Theory. It was originally composed of 55 Likert scale items with three options related to locus and controllability causal dimensions. It was applied in a sample of 668 basic education students. The factor analysis revealed the good functioning of 35 items and identified a two-factor structure: fator 1 causes for failure and factor 2 causes for success. Its internal consistency was assessed by Cronbach Alpha and was, respectively, 0,91 for the total scale, 0,92 for factor 1 and 0,83 for factor 2 . The total variance explained was $29,03 \%$. It is the hope that the scale can be useful for researchers and educators.

Keywords: causal attribution; basic education; instrument construction.

A Teoria da Atribuição de Causalidade é uma das teorias sociocognitivas da motivação escolar e acadêmica. Como descrito em Boruchovitch e Martini (1997), as teorias sociocognitivas da motivação assumem que o comportamento é mediado pelas crenças individuais do aluno e diferem entre si com relação às crenças que enfatizam. Estudos têm-se concentrado em analisar o impacto dessas crenças no desempenho do estudante. As atribuições de causalidade para situações de sucesso e de fracasso escolar, a autocompetência e a autoeficácia, entre outras crenças, têm rece- bido muita atenção de pesquisadores (Bandura, 1982, 1989; Schunk, Pintrich, \& Meece, 2008; Weiner, 1985; 2010; Stipek \& Daniels, 1988). Estudiosos concordam com a ideia de que as atribuições que o sujeito dá a si mesmo de seus êxitos e fracassos ou da conduta dos demais exercem um papel central na teoria geral da motivação (Weiner, 2010; Zimmerman, 2011). Pesquisas revelam que as atribuições de causalidade relativas a experiências de sucesso e de fracasso escolar exercem influência significativa na motivação para a aprendizagem e no desempenho escolar subsequente. 
Causas internas, controláveis e estáveis em geral associam-se positivamente ao sucesso no contexto educativo (Boruchovitch, 1994; Martini \& Del Prette, 2002; Miranda, Almeida, Boruchovitch, Almeida, \& Abreu, 2012; Schunk et al., 2008).

Atribuir causas é uma tendência humana. As pessoas se preocupam em compreender o ambiente em que vivem, os fatos que ocorrem ao seu redor e também buscam explicá-los atribuindo-lhes determinadas causas. De acordo com Weiner (1985), a teoria da atribuição de causalidade integra pensamento, sentimento e a ação. Nessa teoria, o ser humano é visto como alguém que tenta entender e atribuir causas aos eventos que lhe acontecem. Indivíduos, geralmente, tendem a interpretar suas experiências de sucesso e de fracasso em termos de quatro fatores: inteligência, esforço, dificuldade da tarefa e sorte. Causas são entendidas como tendo três dimensões: localização, controlabilidade e estabilidade. Em termos da localização, uma causa pode ser considerada como externa ou interna (fatores que se encontram fora ou dentro do indivíduo). No que se concerne à controlabilidade, uma causa pode ser vista como estando dentro ou fora do controle de uma pessoa. No que diz respeito à estabilidade, uma causa pode ser entendida como sendo permanente ou passível de mudança.

Weiner (1985) reporta que, em termos das três dimensões da causa, a inteligência é vista como uma causa interna, isto é, pertencente ao sujeito, estável (imutável) e fora do controle do indivíduo. O esforço é concebido como uma causa interna, instável (pode ser alterado) e controlável (monitorado) pelo sujeito. Tanto a dificuldade da tarefa quanto a sorte são vistas como causas externas, instáveis e fora do controle do indivíduo.

Segundo Weiner (1985), a estabilidade da causa é a dimensão mais importante no que toca às realizações subsequentes do sujeito. Se um aluno acredita que o seu fracasso escolar é causado por um fator estável (por exemplo, falta de inteligência), ele julgará que há pouco a fazer em termos de suas futuras realizações escolares e terá expectativas de que fracassará novamente. Dessa forma, as atribuições de causalidade influenciam as expectativas futuras de sucesso do aluno e elas, por sua vez, exercem um impacto no pensamento do indivíduo e no seu curso de ação.

Embora se constate que as pesquisas sobre as atribuições causais, no contexto educativo brasileiro, têm sido ampliadas nos diversos segmentos da escolarização, a quantidade de estudos existentes ainda é pequena, sobretudo quando se leva em conta a relevância desse construto para a compreensão da motivação e do desempenho escolar de estudantes. As pesquisas de Boruchovitch (2004), Ferreira et al. (2002), Ganda e Boruchovitch (2012), Garcia e Boruchovitch (2014), Garcia e Boruchovitch (2015), Martini e Del Prette (2005), Neves e Almeida (1996), Piccinini (1989) e Rodrigues (1984) constituemexemplos de publicações sobre o tema recuperadas na literatura brasileira.

Uma questão que merece destaque diz respeito às formas de avaliar as atribuições causais. Existem diversas escalas e questionários na literatura internacional, com estudos que mostram evidências de validade e precisão para o uso no contexto educativo. Como exemplos, podem ser citadas: Children Attributional Style Questionnaire (Seligman, Abramson, Semmel, \& von Baeyer, 1979); Causal Dimension Scale (Russell, 1982); Sydney Attribution Scale (Marsh, 1984); Causal Dimension Scale II (MacAuley, Duncan, \& Russell, 1992); Questionário de Atribuições e Dimensões Causais (Pina Neves \& Faria, 2005); Questionário de Atribuições de Resultados Escolares (Almeida \& Miranda, 2005); ATFLL Questionnaire (Pishghadam \& Modarresi (2008).

No Brasil, como revisto por Ganda e Boruchovitch (2012), tem predominado o estudo dessas atribuições por meio de entrevistas, de questões abertas, de questões rápidas de escolha forçada e de cenários ou situações hipotéticas, entre outros procedimentos, nos diferentes níveis da escolarização formal (Boruchovitch \& Martini, 1998; Boruchovitch, 2004; Ferreira et al., 2002; Formiga, 2004; Martini \& Del Prette, 2002; Neves \& Almeida, 1996; Piccinini, 1989; Pilati, Leão, Vieira, \& Fonseca, 2008; Yoshimoto, 2004). Mais precisamente, no Ensino Fundamental, nenhum deles contém exame, nem descrição de suas propriedades psicométricas (Boruchovitch \& Martini, 1997; Boruchovitch, 2004; Martini \& Del Prette, 2002; Neves \& Almeida, 1996; Piccinini, 1989). Evidencia-se, pois, certa carência de instrumentos nacionais para mensurar as atribuições causais de maneira mais objetiva, válida e confiável, sobretudo nos anos iniciais da escolarização formal. Esforços nessa direção têm-se ampliado, sendo o presente trabalho um dos exemplos disso.

Um importante desafio da área de avaliação psicológica nacional contemporânea, certamente, é avançar 
no sentido de fortalecer as iniciativas voltadas à construção de medidas sensíveis à nossa realidade, para o seu emprego em diversos contextos. Pesquisadores concordam quanto à importância do uso de questões abertas e de instrumentos qualitativos como primeiro passo na construção de medidas mais objetivas (Boruchovitch \& Schall, 1999; Günther \& Lopes, 1990; Isaac \& Michael, 1982). Contudo, são necessários passos subsequentes direcionados à elaboração de itens que expressem o que é peculiar em uma dada realidade na operacionalização do construto, ao mesmo tempo em que simplificam a aplicação e produzem resultados generalizáveis por permitirem a construção de medidas, cuja interpretação seja válida e confiável.

É indiscutível a relevância das atribuições causais para a compreensão das variáveis associadas à aprendizagem de qualidade. O conhecimento acumulado acerca dessas atribuições em alunos do ensino fundamental proveniente de pesquisas anteriores com base em questões abertas, de escolha forçada e entrevistas (Boruchovitch \& Martini, 1998; Boruchovitch, 2004; Martini \& Del Prette, 2002; Neves \& Almeida, 1996; Piccinini, 1989), aliada a escassez de instrumentos nacionais para mensurar as atribuições de causalidade de alunos do Ensino Fundamental, de maneira mais objetiva, em nosso meio motivaram a realização da presente pesquisa. Examinar as propriedades psicométricas e estabelecer evidências de validade relativa à estrutura interna dos itens de uma escala construída para avaliar as atribuições de causalidade de alunos do Ensino Fundamental constituíram-se em seus principais objetivos.

\section{MÉTODO}

\section{Participantes}

Fizeram parte do estudo 668 alunos do terceiro ao nono anos do Ensino Fundamental, de ambos os sexos, de duas escolas públicas de duas cidades, uma no interior do Estado de São Paulo (n=393; 58,5\%) e outra do interior do estado de Minas Gerais $(n=275$; 41,5\%). Dos 668 participantes, 113 (17\%) apresentaram respostas incompletas à escala e foram excluídos das análises, o que resultou em uma amostra final de 556 casos válidos. A idade dos estudantes variou de sete a 16 anos, sendo a média de idade 10,5 com um desvio padrão de 1,88 . No que concerne ao sexo, $50,9 \%$ eram do masculino $(n=283)$ e $48,2 \%$, do femi- nino $(\mathrm{n}=268)$ e $0,9 \%(\mathrm{n}=5)$ sem dados de identificação. Dos participantes, $19,6 \%(n=109)$ eram repetentes e $77,5 \%$ não haviam repetido nenhum ano escolar e $2,9 \%(n=16)$ deixou essa questão em branco. No que concerne ao ano escolar, a amostra se distribuiu como se segue: $13,1 \%(n=73)$ encontravam-se no $3^{\circ}$ ano, $18,7 \%(\mathrm{n}=104)$ no $4^{\circ}, 32,9 \%(\mathrm{n}=183)$, no $5^{\circ}, 13,3 \%$ $(\mathrm{n}=74)$ no $6^{\circ}, 9,7 \%(\mathrm{n}=54)$, no $7^{\circ}, 7,0 \%(\mathrm{n}=39)$, no $8^{\circ}$ e $5,2 \%(n=29)$, no $9^{\circ}$ ano escolar.

\section{Instrumento}

\section{Escala de Avaliação das Atribuições de Causalidade para Alunos do Ensino Fundamental (EAVAT-EF)}

A escala de avaliação das atribuições causais, destinada a alunos do Ensino Fundamental, foi construída pelos autores do presente artigo, com base na literatura da área (Russell, 1982; McAuley, Duncan \& Russell, 1992; Weiner, 1979; 1985), levando-se em conta duas das três dimensões da causa: o locus e a controlabilidade. Resultados de pesquisas qualitativas com crianças brasileiras sobre as principais explicações causais para sucesso e fracasso escolar também foram utilizadas para a elaboração de itens para que pudessem ser mais sensíveis e representativos de nossa realidade (Boruchovitch, 2004; Martini \& Boruchovitch, 2009; Neves \& Almeida; 1996; Piccinini, 1989; Schilieper, 2001) tal como recomendado pela literatura referente à construção de instrumentos (Günther \& Lopes, 1990; Isaac \& Michael, 1982). Assim, além das principais atribuições propostas pela teoria (Weiner, 1979; 1985), foram elaborados itens cujo conteúdo emergiu nas análises de estudos nacionais anteriores. Ficar calmo; não ficar nervoso; a professora gostar / não gostar de mim; prestar/ não prestar atenção nas aulas; ser menos bagunceiro, não ficar conversando com os colegas durante as aulas, entre outros, são alguns exemplos desses itens.

A escala consta de 55 itens fechados, do tipo $\mathrm{Li}$ kert, com três opções de respostas: sempre, às vezes e nunca, sendo 31 relacionados a causas explicativas do sucesso e 24 do fracasso no contexto educativo. Após a redação dos itens, seu conteúdo foi avaliado por dois juízes independentes, experts em motivação e conhecedores da teoria de atribuição de causalidade e/ou em avaliação psicoeducacional, que contribuíram para o refinamento do instrumento. Os juízes classificaram os itens em relação às dimensões da causa, com elevado percentual de concordância (acima de 85,5\%). 
Exemplos de questões da escala são: "Tiro boas notas porque fico calmo"; "Vou mal na escola porque minha família não me ajuda" sempre ( ), às vezes, ( ) nunca. As opções valem três pontos para a alternativa "sempre", dois pontos para "às vezes" e um ponto para "nunca". As questões relacionadas às atribuições externas e incontroláveis apresentam essa pontuação invertida. A pontuação total do instrumento pode variar de 55 a 165. Maiores escores na escala correspondem a atribuições mais internas e controláveis.

\section{Procedimentos}

A coleta de dados ocorreu entre março de 2011 e maio de 2012 e iniciada após contato com os diretores de duas escolas públicas para a apresentação dos objetivos da pesquisa e dos cuidados éticos a serem tomados, bem como para consultá-los sobre o seu interesse em participar do estudo. É importante ressaltar que todos os cuidados éticos tomados na presente pesquisa tiveram como base a Resolução n ${ }^{0}$ 196/96, do Ministério da Saúde, com a qual estão em consonância. Após a anuência dos diretores, foi solicitada a autorização dos pais e responsáveis pelos estudantes por meio da assinatura a um termo de consentimento, entregue aos alunos em duas vias. Só fizeram parte da coleta de dados os estudantes cujos responsáveis autorizaram.

Os objetivos da pesquisa foram devidamente explicados para os alunos por estudantes de Pós-Graduação previamente treinados para a coleta de dados. Aos participantes foi assegurado que a pesquisa não influenciaria a nota, não afetaria o seu desempenho na escola, além de garantido o seu caráter estritamente confidencial. Os alunos foram livres para participar ou não.

A escala foi aplicada coletivamente, em pequenos grupos, nas salas de aula disponíveis e cedidas pelas escolas, em horário de maior conveniência dos professores. Os aplicadores, previamente treinados, seguiram as instruções que acompanham e padronizam sua aplicação. Antes de responderem aos itens da escala, solicitou-se aos participantes que preenchessem ques- tões sobre seus dados de identificação, que constavam na própria escala, bem como que respondessem a um item de exemplo para avaliar a compreensão do procedimento. Os aplicadores liam pausadamente cada item e aguardavam o seu preenchimento por parte dos alunos. Em caso de dúvida, os estudantes eram orientados a levantarem a mão. $\mathrm{O}$ tamanho dos grupos incluiu um mínimo de oito a um máximo de 35 , variando de acordo com o ano escolar, sendo menor para as iniciais. O tempo gasto para o preenchimento do instrumento variou de quinze a vinte minutos.

\section{Análise de dados}

$\mathrm{O}$ exame da estrutura fatorial e das propriedades psicométricas da EAVAT-EF foi realizado por meio dos procedimentos estatísticos. A análise da fatorabilidade da escala foi feita pelos Testes de Esfericidade de Bartlett e de Kaiser-Meyer-Olkin (KMO). Para a identificação da estrutura fatorial da medida, foi empregada a Análise Fatorial Exploratória, sendo escolhido o método dos componentes principais (eigenvalue superior a 2,0) e a rotação Varimax.

\section{RESULTADOS E DISCUSSÃO}

Resultados provenientes dos procedimentos indicados revelaram que há um nível de probabilidade muito adequado para a correlação entre itens $\left(\mathrm{X}^{2}\right.$ [1485, N=556]=109005,93; $p<0,001)$. A amostra, averiguada pelo índice de Kaiser-Meyer-Olkin (KMO), 0,91, é apropriada para a realização da Análise Fatorial (Pereira, 2001).

A matriz rotada foi obtida, tendo-se adotado o critério de carga fatorial de 0,30 para a inclusão dos itens, valor mínimo recomendado pela literatura (Crocker \& Algina, 1986; Kline, 1994). Foi realizada a análise da sedimentação para melhor avaliar a adequação do número de fatores, tal como consta na Figura 1 . 


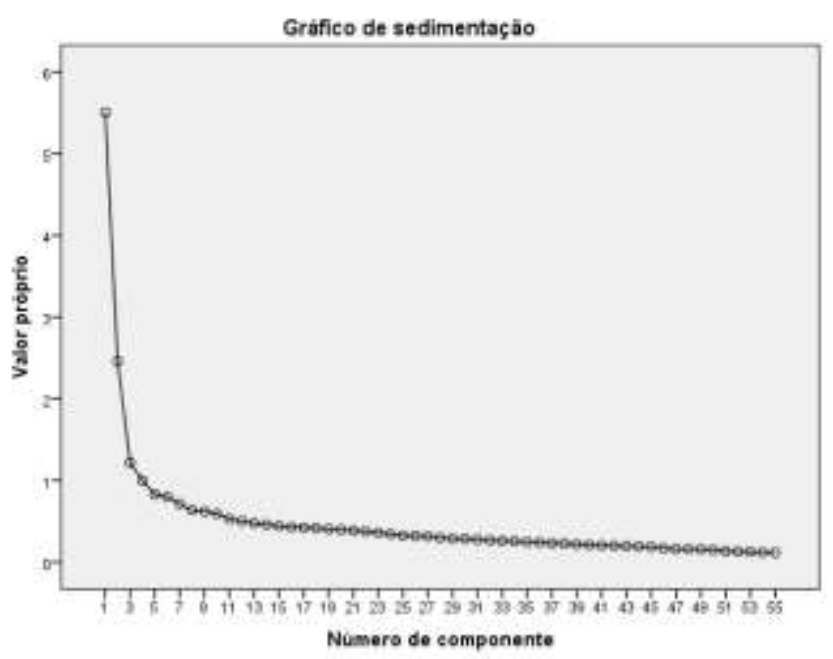

Figura 1. Gráfico de sedimentação dos componentes da escala.

O gráfico de sedimentação da Figura 1 forneceu a estimativa de quatro possíveis fatores, o que seria inicialmente esperado do ponto de vista teórico. No entanto, a análise dos componentes principais (PC) apontou, como a melhor estrutura para o instrumento, a organização dos itens em dois fatores, sendo pertinente denominar o Fator 1 de Causas para Fracasso e o Fator 2 de Causas para Sucesso. Tendo em vista a coerência teórica da organização dos itens em dois fatores, bem como a consistência entre a configuração obtida com tendências humanas em atribuir causas aos eventos que lhe acontecem apontadas na literatura, que serão discutidas mais adiante (Fletcher \& Ward, 1978; Ferreira et al., 2002; Miller \& Ross, 1975; Rus- sell, 1982) optou-se, então por considerar a escala como, de fato, de estrutura bidimensional.

Assim, o Fator 1, Causas para Fracasso, foi composto por 18 itens dos 24 originalmente propostos ( 32 , $33,34,36,37,38,39,41,42,43,46,47,48,49,50$, 52,53 e 54), com saturação variando entre 0,49 e 0,73, com autovalores de 11,05, explicando 20,09\% da variância total. O Fator 2, Causas para o Sucesso, foi composto por 17 itens, dos 31 iniciais $(1,2,3,4,7$, $9,11,15,16,17,22,23,24,26,28,29$ e 31$)$, com saturação variando entre 0,41 e 0,63 , com autovalores de 4,97, explicando $8,94 \%$ da variância total. Os dois fatores permitiram que apenas $29,03 \%$ da variabilidade da escala fossem explicados. Tais itens são identificados na Tabela 1.

Tabela 1.

Distribuição dos Itens por Fator com a Respectiva Carga Fatorial em ordem decrescente

\begin{tabular}{|c|c|c|}
\hline \multirow{2}{*}{ ITENS DA ESCALA } & \multicolumn{2}{|c|}{ CARGAS FATORIAIS } \\
\hline & FATOR 1 & FATOR 2 \\
\hline 54- Vou mal na escola porque minha família não me ajuda. & 0,737 & \\
\hline 48- Não consigo fazer com que minha família me apoie. & 0,715 & \\
\hline 47- Não consigo fazer nada para prestar mais atenção nas aulas. & 0,698 & \\
\hline 49- Respondo errado à professora porque não sou uma pessoa de sorte. & 0,690 & \\
\hline 50- Tiro notas baixas porque os meus colegas não me ajudam. & 0,685 & \\
\hline 41- Tiro notas baixas porque não recebo apoio da minha família. & 0,680 & \\
\hline 46- Sou um mau aluno porque as tarefas da escola são difíceis para mim. & 0,678 & \\
\hline 36- Tiro notas baixas porque não tenho bons professores. & 0,677 & \\
\hline 39- Vou mal na escola porque a professora não gosta de mim. & 0,668 & \\
\hline 34- Vou mal na escola porque os meus professores não explicam bem as matérias. & 0,656 & \\
\hline
\end{tabular}




\begin{tabular}{|c|c|c|}
\hline 37- Não consigo fazer nada para ser mais esforçado. & 0,649 & \\
\hline 38- Não consigo fazer nada para estudar melhor. & 0,638 & \\
\hline 43- Não consigo fazer com que os meus colegas me ajudem. & 0,632 & \\
\hline 42- Não consigo fazer nada para que as provas sejam mais fáceis. & 0,619 & \\
\hline 53- Não consigo fazer nada para ficar menos nervoso nas provas. & 0,609 & \\
\hline 52- Não consigo ficar de bom humor na escola. & 0,603 & \\
\hline 32- Não consigo fazer nada para ser mais inteligente. & 0,580 & \\
\hline 33- Não consigo fazer nada para a professora gostar de mim. & 0,495 & \\
\hline 24- Consigo fazer coisas para ser mais inteligente. & & 0,630 \\
\hline 15- Tiro boas notas nas matérias porque fico calmo. & & 0,587 \\
\hline 9- Tenho sucesso na escola porque sou esforçado. & & 0,578 \\
\hline 22- Acerto as perguntas da professora porque presto atenção na aula. & & 0,542 \\
\hline 31- Tenho sucesso na escola porque sei como estudar & & 0,531 \\
\hline 28- Consigo me esforçar para melhorar na escola. & 0,355 & 0,527 \\
\hline 2- Tenho sucesso nas matérias da escola porque me comporto bem. & & 0,522 \\
\hline 26- Sou bom aluno porque não fico conversando com os meus amigos durante a aula. & & 0,515 \\
\hline 29- Consigo ser mais estudioso quando preciso. & 0,309 & 0,512 \\
\hline 23- Consigo fazer coisas para ter mais sorte na escola. & & 0,502 \\
\hline 3- Consigo prestar mais atenção nas aulas. & & 0,488 \\
\hline 1- Tiro boas notas porque sou inteligente. & & 0,477 \\
\hline 4- Consigo fazer coisas para ficar calmo nas provas. & & 0,465 \\
\hline 17- Consigo fazer coisas para que as tarefas da escola sejam mais fáceis. & & 0,464 \\
\hline 16- Consigo melhorar minhas notas quando preciso. & & 0,450 \\
\hline 11- Consigo fazer com que a professora goste mais de mim. & & 0,443 \\
\hline 7- Consigo ser menos bagunceiro nas aulas. & & 0,417 \\
\hline
\end{tabular}

Método de Extração: análise dos componentes principais. Método de Rotação: Varimax com Normalização de Kaiser. A rotação convergiu em 3 interações.

A análise detalhada da configuração dos itens nos fatores levou à decisão de manter na escala os itens 28 e 29 que apresentaram carga em mais de um fator, já que a mais elevada se deu no fator esperado e excluir vinte itens $(5,6,8,10,12,13,14,18,19,20,21,25$, $27,30,35,40,44,45,51$ e 55$)$ que não funcionaram bem pelas seguintes razões: tiveram cargas negativas no fator esperado, não alcançaram carga mínima em nenhum dos fatores, carregaram no fator não esperado ou tiveram cargas de valores muito próximas nos dois fatores. Entre eles, 14 foram relativos às atribuições de sucesso e seis de fracasso. Como alguns exemplos desses itens, podem ser citados o item 5 "Sou um bom aluno porque as tarefas da escola são fáceis"; o 12 "Consigo ajuda dos colegas quando eu preciso", o 35 "Vou mal na escola por que sou burro" e o 51 "Vou mal na escola porque não sou esforçado", entre outros.
Um exame aprofundado de todos os itens que foram excluídos permitiu constatar que, em relação às causas de sucesso, com exceção dos itens 20, 27 e 30, respectivamente "Consigo deixar de ser bagunceiro na hora que eu quiser"; "Tenho sucesso na escola porque fico calmo" e "Tenho sucesso na escola porque sou estudioso", de controle e locus interno, não funcionaram bem, predominantemente, todos os itens nos quais o sucesso era atribuído e associado a fatores externos e nos quais controle era visto também como supostamente fora do sujeito (ajuda dos amigos, da família e da professora, sorte, a professora explicar bem e a professora gostar do aluno). No que diz respeito ao fracasso, o conteúdo dos itens excluídos se relacionou às atribuições internas e, na maior parte das vezes, passíveis de serem controladas pelo indivíduo (ser burro, fazer bagunça, não prestar atenção à 
aula, sentir-se cansado, não ser esforçado e ficar nervoso nas provas).

Dessa forma, a escala original de 55 itens ficou composta de 35 itens nos quais, com poucas exceções, o sucesso é atribuído a fatores internos e controláveis pelo sujeito e o fracasso a causas externas e de controle externo, bem como a causas nas quais há falta de controle interno (Item 37- "Não consigo fazer nada para ser mais esforçado"). Da concepção original na qual foram construídos itens que tentassem mapear o locus e o controle interno e o locus e o controle externo, emergiu uma escala de dois fatores, que possibilita avaliar as atribuições de sucesso para causas internas e controláveis, tanto pelo sujeito ou por razões fora de seu alcance, bem como as atribuições de fracasso a causas externas e controláveis interna e externamente.

Pode-se dizer que a escala final que emergiu no presente estudo é coerente com alguns resultados de pesquisa (Fletcher \& Ward, 1978; Miller \& Ross, 1975; Russell, 1982) nos quais fica clara a presença da tendência autosservidora, que faz com que os estudantes tendam a proteger seu ego e sua autoestima da responsabilidade pelas experiências de fracasso, atribuindo-as a causas externas, ao passo que os sucessos são interpretados com base em causas internas e controláveis. Aventam Fletcher e Ward (1978) que essa tendência autosservidora possa ser uma forma predominante de lidar com as atribuições em diversas culturas.

Entretanto, um olhar atento aos dados provenientes da literatura nacional, nos quais medidas mais qualitativas foram empregadas para examinar as atribuições dos estudantes, (em vez de escalas) revela, como sintetizam Ferreira et al., 2002, o predomínio de atribuições internas para o sucesso e atribuições mistas (internas e externas) para o fracasso. A internalização do fracasso foi, inclusive, mais frequente, quando a causa era vista como passível de controle pelo indivíduo. Essas diferenças são instigantes para a área de avaliação psicodeducacional e revelam a importância do exame conjunto das dimensões locus e controlabilidade, bem como a necessidade de que instrumentos qualitativos e quantitativos possam ser aperfeiçoados de forma a obterem dados mais convergentes.

Com relação à precisão, estimada pelo coeficiente de Cronbach, a escala total com 35 itens e cada um dos fatores alcançaram índices plenamente satisfatórios de consistência interna, de acordo com os critérios de Prieto e Muñiz, (2000), que foram 0,91 para escala total, 0,92 para o fator 1 e 0,83 para o fator 2 .

\section{CONSIDERAÇÕES FINAIS}

Acredita-se que o presente estudo seja relevante, pois, ao que tudo indica, é uma das primeiras iniciativas, em nível nacional, no sentido de tentar desenvolver um instrumento de medida objetivo das atribuições causais de estudantes do Ensino Fundamental. Pode-se dizer que a EAVAT-EF é um instrumento simples, com parâmetros psicométricos iniciais bons e que mede grande parte daquilo a que ela inicialmente se propôs, isto é, as principais atribuições causais para sucesso e fracasso escolar nas dimensões locus e controle da causa. Sua construção teve a intenção de oferecer a pesquisadores, psicólogos, psicopedagogos e educadores um instrumento que identificasse, mais prontamente, a que fatores os estudantes brasileiros do Ensino Fundamental atribuem suas experiências de sucesso e de fracasso no contexto escolar.

Cabe mencionar que EAVAT-EF se propõe a medir a tendência atribucional geral que o estudante possui diante de suas vivências relacionadas à aprendizagem. Deve se, entretanto, ter em mente que as atribuições causais podem variar de acordo com cada contexto de aprendizagem, disciplina específica ou até mesmo de tarefa para tarefa (Hessling, Anderson, \& Russell, 2002; Russell, 1982). Em consonância, sugere-se que versões da escala mais adaptadas a contextos específicos sejam também desenvolvidas e testadas.

Ademais, destaca-se a necessidade de que futuros estudos sejam conduzidos para testar novos itens de atribuição de sucesso a causas externas e incontroláveis e de fracasso a causas internas e controláveis, que sejam mais sensíveis aos possíveis vieses atribucionais, uma vez que os itens com essas características específicas não funcionaram bem no instrumento do presente estudo. Buscando superar outra limitação do presente estudo, investimentos devem também ser realizados no sentido aperfeiçoar a presente escala, acrescentando-lhe mais uma dimensão: a estabilidade da causa, já que a teoria mostra que ela é a dimensão causal, tanto para as experiências de sucesso quanto para as de fracasso que mais influencia o comportamento subsequente (Weiner, 1979; 1985).

Faz-se necessário também que a presente escala, com os refinamentos necessários, seja aplicada em amostras maiores e representativas, em âmbito nacional, bem como possa ser correlacionada a variáveis de interesse que permitam o exame de outras possíveis evidências de validade, como a concorrente e a predi- 
tiva. Estudos referentes à análise de sua estabilidade temporal, por meio de teste e reteste, serão igualmente valiosos, pois ampliarão o exame da validade e confiabilidade da escala de forma que ela possa ser empregada de modo mais criterioso em nosso meio.

Esforços orientados em várias direções possibilitarão melhor compreensão de como essas atribuições se caracterizam, em nosso meio. Há que aquilatar se, de fato, ocorre a tendência autosservidora nos processos atribucionais de alunos do Ensino Fundamental, se o presente instrumento não foi sensível a ponto de captar outros padrões existentes ou, ainda, se essa tendência emergiu apenas como um aspecto peculiar da presente amostra. Pesquisas futuras, certamente, inaugurariam outras discussões acerca não só das potencialidades e dos limites da escala para a avaliação psicoeducacional, mas também colaborariam para o seu refinamento e melhor aproveitamento, no contexto educativo.

\section{REFERÊNCIAS}

Almeida, L. S., \& Miranda, L. (2005). Questionário de atribuições de resultados escolares - QARE. Braga: Universidade do Minho.

Bandura, A. (1982). Self-efficacy mechanism in human agency. American Psychologist, 37, 122-147.

Bandura, A. (1989). Regulation of cognitive processes though perceived self-efficacy. Development Psychology, 25(5), 729-735.

Boruchovitch, E. (1994). As variáveis psicológicas e o processo da aprendizagem: Uma contribuição para a psicologia escolar. Psicologia: Teoria e Pesquisa, 20 (1), 129-139. DOI: 10.1590/S0102-37722004000100010.

Boruchovitch, E. (2004). A study of causal attributions for success and failure in mathematics among Brazilian students. Revista Interamericana de Psicologia, 38(2), 5360.

Boruchovitch, E., \& Martini, M. L. (1997). As atribuições de causalidade para sucesso e fracasso escolar e a motivação para aprendizagem de crianças brasileiras. Arquivos Brasileiros de Psicologia, 44 (3), 59-71.

Boruchovitch, E., \& Schall, V. T. (1999). Questionnaires in health education research. Advantages and disadvantages of open ended questions. Implications for health research methodology. Ciência e Cultura, 51(1), 12-15.

CNS (Conselho Nacional de Saúde). Resolução 196/96. Diretrizes e normas regulamentadoras de pesquisas envolvendo seres humanos. Retirado de http://conselho. saude.gov.br/resolucoes/reso_96.htm.
Crocker, L., \& Algina, J. (1986). Introduction to classical \& modern test theory. Orlando, Florida: Holt, Rinehart and Winston, Inc.

Ferreira, M., Assmar, E., Omar, A., Delgado, H., González, A., Souza, M., \& Cisne, M. (2002). Atribuições de causalidade ao sucesso e fracasso escolar: Um estudo transcultural Brasil-Argentina-México. Psicologia: Reflexão e Crítica, 15 (3), 515-527. DOI: 10.1590/S0102-79722 002000300006 .

Fletcher, G. J. O., \& Ward, C. (1978). Attribution theory and processes: A cross-cultural perspective. Em M. H. Bond (Ed.), The cross-cultural challenge to Social Psychology (pp. 230-244). Newsbury Park, CA: Sage.

Formiga, N. (2004). Atribuição de causalidade e rendimento acadêmico: predição e diferença em alunos da universidade pública e privada. Revista de Psicologia da UNC, 2(1), 3-14.

Ganda, D. R., \& Boruchovitch, E. (2012). Avaliação da atribuição de causalidade em contexto educacional. Em E. Boruchovitch, A. A. A. Santos, \& E. Nascimento (Eds.), Avaliação psicológica nos contextos educativo e psicossocial (pp. 181-202). São Paulo, SP: Casa do Psicólogo.

Garcia, N. R., \& Boruchovitch, E. (2014). Atribuição de causalidade para o desempenho escolar e a resiliência em estudantes. Psico-USF, 19 (2), 277-286. DOI: 10.1590/ 1413-82712014019002003.

Garcia, N. R., \& Boruchovitch, E. (2015). As atribuições de causalidade no ensino fundamental: relações com variáveis demográficas e escolares. Psico, 46 (2), 176-187. DOI:

10.15448/1980-8623.2015.2.17642.

Günther, H., \& Lopes, Jr., J. (1992). Perguntas abertas versus perguntas fechadas: uma comparação empírica. Psicologia: Teoria e Pesquisa, 6, 203-213.

Hessling, R. M., Anderson, C. A., \& Russell, D. W. (2002). Attributional styles. Em R. Fernandez-Ballesteros (Ed.), Encyclopedia of Psychological Assessment (pp. 116120). London: Sage.

Isaac, S., \& Michael, W. B. (1982). Handbook in research and evaluation. San Diego: Edits I \& M.

Kline, P. (1994). An easy guide to factor analysis. New York: Routledge.

Marsh, H. (1984). The relationship among dimensions of self-attribution dimensions of self-concept and academic achievement. Journal of Educational Psychology, 76, 1291-1308. DOI: 10.1037/0022-0663.76.6.1291

Martini, M. L., \& Boruchovitch. (2009). A Compreensão do sucesso e fracasso escolar por crianças brasileiras. Em E. Boruchovitch, \& J. A Bzuneck (Eds), A Motivação do Aluno: Contribuições da Psicologia Contemporânea ( $4^{\mathrm{a}}$ ed., pp. 148-166). Petrópolis, RJ: Editora Vozes. 
Martini, M. L., \& Del Prette, Z. A. P. (2002). Atribuições de Causalidade para o sucesso e fracasso escolar dos seus alunos por professores do Ensino Fundamental. Interação em Psicologia, 6(2), p. 149-156.

Martini, M. L., \& Del Prette, Z. A. P. (2005). Atribuições de causalidade e afetividade de alunos de alto e baixo desempenho acadêmico em situações de sucesso e de fracasso escolar. Interamerican Journal of Psychology, 39 (3), 355-368.

McAuley, E., Duncan, T. E., \& Russell, D. W. (1992). Measuring causal attributions: The revised Causal Dimension Scale (CDS II). Personality and Social Psychology Bulletin, 18, 566-573. DOI: 10.1177/014616729 2185006

Miller, D. T., \& Ross, M. (1975). Self-serving bias in attribution causality: Fact or fiction? Psychological Bulletin, 82, 213-225.

Miranda, L. C., Almeida, L. S., Boruchovitch, E. Almeida, A. R., \& Abreu, S. (2012). Atribuições causais e nível educativo familiar na compreensão do desempenho escolar em alunos portugueses. Psico-USF, 17(1), 1-9. DOI: 10.1590/S1413-82712012000100002.

Neves, M. B. J., \& Almeida, S. F. C. (1996). O fracasso escolar na $5^{\mathrm{a}}$ série, na perspectiva de alunos repetentes, seus pais e professores. Psicologia: Teoria e Pesquisa, 12, 147-156.

Pereira, J. C. R. (2001). Análise de dados qualitativos: Estratégias metodológicas para as Ciências da Saúde, Humanas e Sociais. São Paulo: EDUSP.

Piccinini, C. A. (1989). Atribuições de causalidade em crianças: Alguns aspectos críticos. Psicologia: Teoria e Pesquisa, 5(1), 57-69.

Pilati, R., Leão, M., Vieira, J., \& Fonseca, M. (2008). Efeitos da atribuição de causalidade e custo pessoal sobre a intenção de ajuda. Estudos de Psicologia (Natal), 13(3), 213-221. DOI: 10.1590/S1413-294X2008000300004.

Pina Neves, S., \& Faria, L. (2005). Questionário de atribuições e dimensões causais (QADC): Análises factoriais exploratórias e diferenças entre $9^{\circ}$ e $10^{\circ}$ anos. Manuscrito não publicado. Universidade da Madeira-PT.

Pishghadam, R., \& Modarresi, G. (2008). The construct validation and application of questionnaire of attribution theory for foreign language learners. Iranian Journal of Language Studies, 2(3), 299-324.

Prieto, G., \& Muñiz, J. (2000). Um modelo para evaluar la calidad de los tests utilizados em España. Recuperado de http://www.cop.es/tests/modelo.htm.

Rodrigues, A. (1984). Atribuição de causalidade: estudos brasileiros. Arquivos Brasileiros de Psicologia, 36(2), 520.
Russell, D. (1982). The causal dimension scale: A measure of how individuals perceive causes. Journal of Personality and Social Psychology, 42(6), 1137-1145.

Schilieper, M. D. M. J. (2001). As estratégias de aprendizagem e as atribuições de causalidade de alunos do ensino fundamental (Dissertação de Mestrado). Universidade Estadual de Campinas, Campinas, São Paulo, Brasil.

Schunk, D., Pintrich, P., \& Meece, J. L. (2008). Motivation in education: Theory, research and applications. Upper Saddle River, New Jersey: Pearson Merrill Prentice Hall.

Seligman, M. E. P., Abramson, L. Y., Semmel, A., \& von Baeyer, C. (1979). Depressive attributional style. Journal of Abnormal Psychology, 88, 242-247.

Stipek, D. C., \& Daniels, D. H. (1988). Declining perceptions of competence: a consequence of changes in the child or in the educational environment? Journal of Educational Psychology, 80(3), 352-356.

Zimmerman, B. J. (2011). Motivational sources and outcomes of self-regulated learning and performance. In B. Zimmerman, \& D. Schunk (Eds.), Handbook of selfregulation of learning and performance (pp. 49-64). New York, NY: Routledge, Taylor \& Francis Group.

Weiner, B. (1979). A theory of motivation for some classroom experiences. Journal of Educational Psychology, 71(1), 3-25. DOI: 10.1037/0022-0663.71.1.3

Weiner, B. (1985). An attributional theory of achievement motivation and emotion. Psycological Rewiew, 92 (4), 548-573.

Weiner, B. (2010). The development of an attribution-based theory of motivation: A history of ideas. Educational Psychologist, 45(1), 28-36. DOI: 10.1080/0046152090 3433596.

Yoshimoto, C. R. (2004). Análise atribucional do baixo rendimento escolar em alunos da quarta série do ensino fundamental, participantes do projeto "Escola nas Férias" (Dissertação de Mestrado). Universidade Estadual Paulista, Marília - São Paulo, Brasil. 